\title{
Arabidopsis thaliana EDS4 Contributes to Salicylic Acid (SA)-Dependent Expression of Defense Responses: Evidence for Inhibition of Jasmonic Acid Signaling by SA
}

\author{
Vaijayanti Gupta, ${ }^{1,3}$ Michael G. Willits, ${ }^{2}$ and Jane Glazebrook ${ }^{3}$ \\ ${ }^{1}$ Molecular and Cell Biology Graduate Program, University of Maryland, College Park 20742, U.S.A.; \\ ${ }^{2}$ Novartis Agribusiness Biotechnology Research, Inc., P.O. Box 12257, 3054 Cornwallis Road, Research \\ Triangle Park, NC 27709-2257, U.S.A.; ${ }^{3}$ Novartis Agricultural Discovery Institute, Inc., 3115 Merryfield \\ Row Ste.100, San Diego, CA 92121, U.S.A. \\ Accepted 7 January 2000.
}

The Arabidopsis enhanced disease susceptibility 4 (eds 4$)$ mutation causes enhanced susceptibility to infection by the bacterial pathogen Pseudomonas syringae pv. maculicola ES4326 (Psm ES4326). Gene-for-gene resistance to bacteria carrying the avirulence gene avrRpt2 is not significantly affected by eds4. Plants homozygous for eds4 exhibit reduced expression of the pathogenesis-related gene PR-1 after infection by Psm ES4326, weakened responses to treatment with the signal molecule salicylic acid (SA), impairment of the systemic acquired resistance response, and reduced accumulation of $\mathrm{SA}$ after infection with $\boldsymbol{P} \mathbf{S m}$ ES4326. These phenotypes indicate that EDS4 plays a role in SA-dependent signaling. SA has been shown to have a negative effect on activation of gene expression by the signal molecule jasmonic acid (JA). Two mutations that cause reduced SA levels, eds 4 and pad4, cause heightened responses to inducers of JA-dependent gene expression, providing genetic evidence to support the idea that $\mathrm{SA}$ interferes with JA-dependent signaling. Two possible working models of the role of EDS4 in governing activation of defense responses are presented.

When pathogenic microorganisms attack plants, the plants activate a battery of defense responses to fight the spread of infection. In some plant-pathogen interactions, products of pathogen genes called avirulence ( $a v r$ ) genes are recognized by products of corresponding resistance $(R)$ genes in the host, resulting in rapid activation of host defense responses. Typically, an $R$ gene recognizes only a single $a v r$ gene, so this form of resistance is called gene-for-gene resistance (Baker et al. 1997). During gene-for-gene resistance responses, the infected plant cells undergo a form of rapid, programmed cell death called the hypersensitive response (HR) (Hammond-Kosack and Jones 1996). Pathogens that trigger gene-for-gene resistance are called avirulent pathogens. If the pathogen does not carry an avr gene recognized by the

Corresponding author: Jane Glazebrook; Telephone: 1-858-812-1075; Fax: 1-858-812-1105; E-mail: jane.glazebrook@nadii.novartis.com plant, it does not elicit an HR, defense responses are activated more slowly, and disease ensues. Such pathogens are called virulent pathogens.

Infection by an avirulent pathogen causes the dying cells in the locally infected tissue to emit a signal that activates systemic acquired resistance (SAR) in distant tissues of the plant. Plants can acquire resistance to normally virulent pathogens through SAR. SAR is characterized by the enhanced expression of defense genes such as pathogenesis-related $(P R)$ genes like $P R-1, P R-5$, and $B G L-2$ in the systemic tissues. Salicylic acid (SA) plays a key role in activation of SAR (HammondKosack and Jones 1996; Durner et al. 1998). Exogenous application of SA is sufficient to induce SAR and activate $P R-1$ defense gene expression (Ryals et al. 1996). The requirement for SA as a signal in SAR was proven by construction of transgenic plants expressing a bacterial salicylate hydroxylase gene $(n a h G)$ that converts SA to catechol (Gaffney et al. 1993). When infected with pathogens that induce SAR in wild-type plants, nahG plants fail to develop SAR and do not exhibit systemic expression of $P R$ genes (Delaney et al. 1994). While it is clear that SA is required in the systemic tissues for $P R$ gene expression, it does not appear to be the translocated signal (Vernooij et al. 1994; Willits and Ryals 1998). SA has also been found to play an important role in the induction of defense gene expression in the local tissues (Delaney et al. 1994). Arabidopsis $n a h G$ plants are compromised in local resistance, displaying enhanced susceptibility to a variety of virulent and avirulent pathogens (Delaney et al. 1994; Lawton et al. 1995; Reuber et al. 1998).

Genetic analysis has revealed some components of the signal transduction pathways that control activation of defense responses. Several mutants with defects in genes required for the activation of the SA signaling pathway have been characterized. Plants carrying pad4 mutations display reduced SA accumulation, reduced $P R-1$ expression, and low levels of the antimicrobial metabolite camalexin in leaves infected with the virulent bacterial pathogen Pseudomonas syringae pv. maculicola ES4326 (Psm ES4326) (Zhou et al. 1998). SA is necessary and sufficient for activation of $P R-1$ expression, and necessary but not sufficient for camalexin synthesis (Zhou et al. 
1998). The defense response defects in pad4 plants appear to be due to inadequate SA accumulation in response to infection because they can be suppressed by exogenous application of SA (Zhou et al. 1998). Consequently, PAD4 is thought to act by promoting SA accumulation, leading to activation of SAdependent defense responses (Zhou et al. 1998).

When plants carrying eds5 (sidl, salicylic acid inductiondeficient 1 ) or sid 2 mutations are infected with $P$. syringae, they accumulate very little SA and $P R-1$ transcript (Nawrath and Metraux 1999; Rogers and Ausubel 1997). Unlike pad4 plants, eds 5 and sid2 plants do not have defects in camalexin synthesis (Nawrath and Metraux 1999). Treatment with SAR activators BTH (benzothiadiazole) or INA (2,6-dichloroisonicotinic acid) activates $P R-1$ expression in eds 5 and sid2 plants. Taken together, these phenotypes suggest that EDS5 and SID2 act upstream from SA accumulation in a way that does not interfere with activation of camalexin synthesis (Nawrath and Metraux 1999).

Mutants with defects in a gene called $n p r l$ (non-inducer of PR proteins) or niml (non-inducible immunity) do not express $P R$ genes in response to exogenous SA (Cao et al. 1994; Delaney et al. 1995; Shah et al. 1997). Mutations in NPRI cause increased susceptibility to $P$. syringae, reduced $P R-1$ expression in infected leaves, and failure to establish SAR (Cao et al. 1994; Delaney et al. 1995; Glazebrook et al. 1996; Shah et al. 1997). In contrast to pad4, eds5, and sid2 plants, in nprl plants SA accumulation is higher than it is in wild-type plants. These phenotypes indicate that NPRI acts downstream from SA (Cao et al. 1994). Yeast two-hybrid experiments showed that NPR1 interacts with b-zip transcription factors that bind to the $P R-1$ promoter, suggesting that NPRI promotes defense gene expression by altering the activities of transcription factors (Zhang et al. 1999).

Arabidopsis has also been used to study the role of jasmonic acid (JA)-dependent signaling in disease resistance. Chemicals such as methyl jasmonate (MeJA), an ester that releases JA, or rose bengal, an oxidizing agent, act in a JAdependent manner to induce local and systemic production of a set of plant defense proteins including thionins (Epple et al. 1995) and defensins (Penninckx et al. 1996). Infection by the fungal pathogen Alternaria brassicicola activates the expression of the defensin gene PDF1.2 in a JA-dependent manner (Penninckx et al. 1996). JA-dependent responses must be important for resistance to A. brassicicola, since pre-treatment with MeJA enhances resistance (Penninckx et al. 1996), and the coil mutation, which blocks responses to JA, compromises resistance (Feys et al. 1994).

SA-dependent signaling and JA-dependent signaling can be mutually inhibitory. In tobacco, SA inhibits transcription of genes encoding enzymes required for JA synthesis (Harms et al. 1998; Nishiuchi et al. 1997). Moreover, SA treatment inhibits JA-mediated activation of basic $P R$ gene expression while JA treatment inhibits SA-mediated activation of acidic $P R$ gene expression (Niki et al. 1998). Several Arabidopsis mutants with defects in SA signaling display enhanced sensitivity to inducers of JA-dependent expression of PDF1.2. Plants carrying $n a h G$, which fail to accumulate SA, and $n p r l$ plants, which fail to respond to SA, express PDF1.2 at higher levels than wild-type plants when infected with $A$. brassicicola or treated with rose bengal (Clarke et al. 1998; Penninckx et al. 1996). Conversely, constitutive expression of PDF1.2 in cpr6 plants is inhibited by treatment with INA, an inducer of SA signaling (Clarke et al. 1998).

A collection of mutants that includes plants with defects in genes required for activation of defense responses was obtained by screening a mutagenized population of Arabidopsis for plants that showed an enhanced disease susceptibility $(e d s)$ phenotype in response to infection by Psm ES4326 (Glazebrook et al. 1996). The eds mutations included alleles of $n p r l$, pad4, and eds5 (Glazebrook et al. 1996). We now describe the characterization of $e d s 4$, another mutant obtained in the eds screen (Glazebrook et al. 1996). We have found that eds 4 plants exhibit reduced accumulation of SA after infection by Psm ES4326, attenuated responses to exogenous SA, and heightened responses to stimulation of JA signaling. These phenotypes led to the conclusion that EDS4 contributes to SA accumulation in response to pathogen attack, as well as to SAinduced activation of defense responses.

\section{RESULTS}

\section{Gene-for-gene resistance to Psm ES4326 carrying avrRpt2 is not affected by eds 4 .}

Previous work showed that susceptibility to the virulent strain Psm ES4326 is enhanced in eds4 plants (Glazebrook et al. 1996). To test for effects of eds 4 on gene-for-gene resistance, we compared growth of Psm ES4326 and an isogenic avirulent strain carrying the avirulence gene avrRpt2. Wildtype and $e d s 4$ plants were infected with each strain, and bacterial titers in infected leaves were determined daily. Figure 1 shows that the titers of both bacterial strains in eds 4 plants were five- to 10-fold higher than in wild-type plants. In both wild-type plants and eds 4 plants, the titer of the avirulent strain was approximately 100 -fold lower than the titer of the virulent strain. In plants that are defective in gene-for-gene resistance due to a mutation in the resistance gene RPS2, which confers resistance to strains carrying avrRpt2, both Psm ES4326 and Psm ES4326 carrying avrRpt2 reach the same

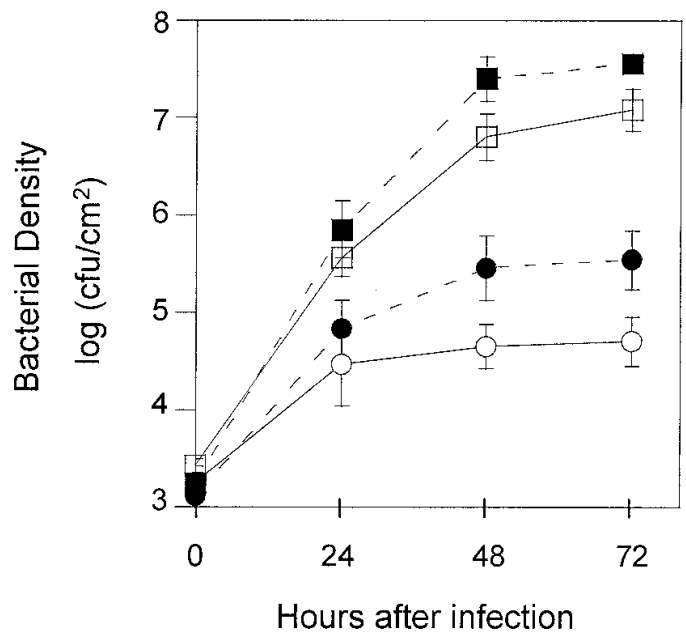

Fig. 1. Bacterial growth in wild type and eds 4 plants. Wild-type (open symbols) and eds4 (closed symbols) plants were infected with Pseudomonas syringae pv. maculicola (Psm) ES4326 (squares) or an isogenic strain carrying the avirulence gene avrRpt2 (circles). Bacterial growth was determined at 24, 36, and $72 \mathrm{~h}$ after infection. Each point represents the mean and standard deviation of six replicates. 
titer as Psm ES4326 does in wild-type plants (Mindrinos et al. 1994). Since titers of Psm ES4326 carrying avrRpt2 were much lower than Psm ES4326 titers in eds4 plants, we concluded that $e d s 4$ does not cause a significant defect in genefor-gene resistance to strains carrying avrRpt2.

\section{Expression of $P R-1$ is impaired in eds 4 plants.}

Some mutants that show enhanced susceptibility to Psm ES4326 also show defects in expression of defense genes after infection by this pathogen (Cao et al. 1994; Zhou et al. 1998; Rogers and Ausubel 1997). To test whether defense gene expression was impaired in eds 4 mutants, we infected wild-type and eds4 plants with Psm ES4326 and monitored mRNA levels of several defense genes at intervals after infection. The levels of $P R-1$ mRNA were reduced in infected $e d s 4$ leaves, compared with the levels in infected wild-type leaves (Fig. 2). This experiment was done three times. The $P R-1$ hybridization signals from all three experiments were measured and normalized to the $18 \mathrm{~S}$ rRNA signals. The ratios of $P R-1$ signal in wild-type plants to $P R-1$ signal in $e d s 4$ plants were calculated. The mean and standard deviation of this value was 1.85 \pm 0.17 at $24 \mathrm{~h}$ and $2.22 \pm 0.05$ at $36 \mathrm{~h}$. Expression of three other genes induced by Psm ES4326 infection-BGL2, PR-5, and $A S A 1$-was not significantly affected by eds4 (data not shown). The finding that $e d s 4$ causes a decrease in the expression of $P R-1$ in response to infection suggests that EDS4 plays a regulatory role in the defense response.

\section{Responses to SA are impaired in eds 4 plants.}

The observation that $e d s 4$ plants have a defect in $P R-1$ expression suggested that eds 4 might interfere with SA signaling. To determine whether eds 4 affects responses to SA, we treated wild-type and $e d s 4$ plants with SA 1 day prior to infection with Psm ES4326. Bacterial growth was measured in the infected leaves at 1,2, and 3 days after infection. When the plants were grown and infected in a Conviron growth chamber under conditions of $22^{\circ} \mathrm{C}$ temperature and $85 \%$ relative humidity, SA treatment reduced the bacterial growth in wild-type plants by about fivefold but did not affect growth in eds 4 plants (Fig. 3A). However, when plants were grown and infected in a constant temperature room under conditions of $23^{\circ} \mathrm{C}$ and $50 \%$ relative humidity, pre-treatment with SA reduced bacterial growth by six- to 10-fold in both wild-type and eds 4 plants (Fig. 3B). These results suggested that eds 4 might cause a partial block in responses to SA-induced resis-

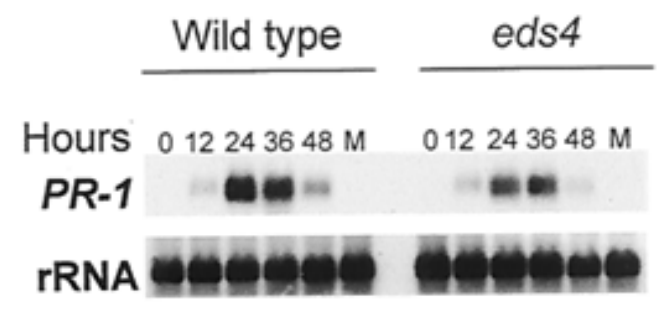

Fig. 2. Expression of $P R-1$ in leaves infected with Pseudomonas syringae pv. maculicola (Psm) ES4326. Leaves were excised at 0, 12, 24, 36, and $48 \mathrm{~h}$ after infection. "M" indicates leaves mock-infected with 10 $\mathrm{mM} \mathrm{MgSO}$ that were sampled at $36 \mathrm{~h} ; 1.5 \mu \mathrm{g}$ of RNA was loaded in each lane; $18 \mathrm{~S}$ rRNA was used as a control for equal loading. tance such that compromised SA-induced resistance is only apparent under some growth conditions.

To test for quantitative effects of eds 4 on responses to SA, wild-type and eds 4 seedlings were grown on medium containing various concentrations of SA. Two weeks after germination, $P R-1$ mRNA levels were examined. At SA concentrations of 0.025 and $0.05 \mathrm{mM}, P R-1$ expression was lower in $e d s 4$ seedlings than it was in wild-type seedlings (Fig. 4). This result confirms that responses to SA are defective in eds 4 plants.

\section{EDS4 is required for resistance to Psm ES4326 and PR-1 expression associated with SAR.}

SA in systemic tissues is required for SAR (Vernooij et al. 1994). Consequently, it is likely that a reduction in the ability
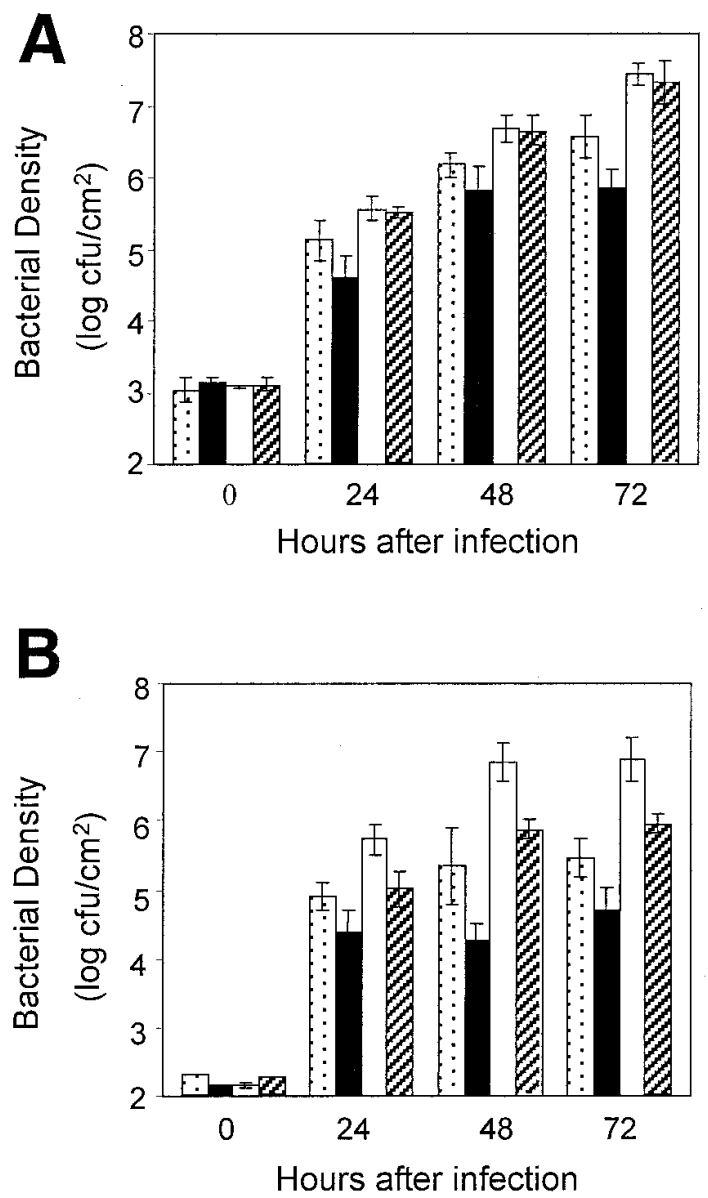

$$
\begin{aligned}
& \text { Wt - 0 mM SA } \because \text { eds } 4 \text { - } 0 \text { mM SA } \square \\
& \text { Wt-5 mM SA } \square \text { eds } 4 \text { - 5mM SA } Z Z
\end{aligned}
$$

Fig. 3. Effect of exogenous salicylic acid (SA) on the growth of Pseudomonas syringae pv. maculicola (Psm) ES4326. Plants were sprayed with $5 \mathrm{mM}$ SA in $0.02 \%$ Silwet or $0.02 \%$ Silwet, until uniformly wet. One day after treatment, plants were infected with bacteria at a dose of $10^{3} \mathrm{CFU} / \mathrm{cm}^{2}$. Bacterial titer was determined at 1,2 , and 3 days after infection. Each bar represents the mean and standard deviation of eight replicates. In four other independent experiments, bacterial titers were determined 3 days after infection and similar results were obtained. A, Plants were grown in a Conviron chamber maintained at $22^{\circ} \mathrm{C}$ and $85 \%$ relative humidity. B, Plants were grown in a constant temperature room, maintained at $23^{\circ} \mathrm{C}$ and $50 \%$ relative humidity. 
to respond to SA would cause a defect in SAR. We tested eds 4 plants for defects in SAR induced by infection with an avirulent pathogen. To induce SAR, four to five leaves of each wild-type and $e d s 4$ plant were infected with $P$. syringae pv. tomato (Pst) DC3000 carrying avrRpt2 or mock-infected with $10 \mathrm{mM} \mathrm{MgSO}$. Four days after infection, two previously uninfected leaves of each plant were challenged with Psm ES4326. In systemic wild-type leaves, the bacterial titer of the virulent strain was reduced by prior infection with Pst DC3000 carrying avrRpt2 (Fig. 5A). Conversely, in eds4 plants, prior infection by Pst DC3000 carrying avrRpt 2 had no effect on growth of Psm ES4326.

Systemic expression of $P R-1$ is also associated with SAR. We tested $e d s 4$ plants for defects in $P R-1$ expression during SAR. SAR was induced by infecting three leaves of each plant with Pst DC3000 carrying avrRpt2. In both wild-type and $e d s 4$ plants, the HR was observed in the infected leaves after $16 \mathrm{~h}$. The HR was not observed in control plants mockinfected with $10 \mathrm{mM} \mathrm{MgSO}$. To examine $P R-1$ expression, uninfected leaves were collected 1, 2, 3, and 4 days after the SAR-inducing infection. $P R-1 \mathrm{mRNA}$ levels in the uninfected leaves of eds 4 plants infected with Pst DC3000 carrying avrRpt 2 were much lower than they were in uninfected leaves of infected wild-type plants (Fig. 5B). Taken together, these results show that eds 4 plants are unable to establish SAR in response to infection by an avirulent pathogen.

\section{$\mathrm{SA}$ accumulation in response to infection is reduced in eds 4 plants.}

We have shown that eds4 plants have a defect in responding to SA. To test for a defect in accumulating SA, we measured the levels of SA and its sugar conjugate, SA glucoside (SAG), in wild-type and eds 4 plants after infection with Psm ES4326. The SA levels in eds4 plants infected with Psm ES4326 were 25, 60, and 50\% of the levels in wild-type plants at 12,24 , and $36 \mathrm{~h}$ after infection, respectively (Fig. 6A), while the SAG levels in eds 4 plants were approximately $50 \%$ of the levels in wild-type plants at all time points tested (Fig. 6B). Taken together, our results suggest that EDS4 is required for accumulation of SA after Psm ES4326 infection, as well as for the efficient activation of $P R-1$ expression in response to $\mathrm{SA}$.

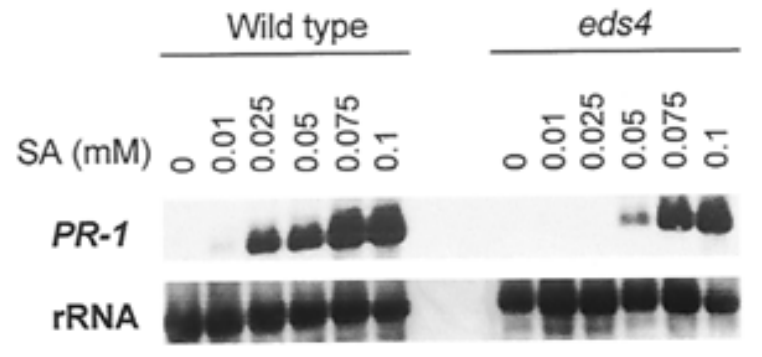

Fig. 4. Effect of salicylic acid (SA) on $P R-1$ expression in wild type and eds 4 seedlings. Expression of $P R-1$ in 2-week-old wild-type and $e d s 4$ seedlings grown in the presence of various concentrations of SA. 18S rRNA was used to evaluate even loading. This experiment was performed three times and similar results were obtained.

\section{Mutations affecting SA signaling cause altered sensitivity to JA signaling.}

The SA-dependent and JA-dependent signal transduction pathways are known to be mutually inhibitory. To test the strength of the correlation between reduced SA signaling and enhanced JA signaling, we examined PDF1.2 expression in pad4 plants. The pad4 mutation causes reduced SA accumulation after infection with Psm ES4326 (Zhou et al. 1998). When pad4 plants and wild-type plants were treated with rose bengal, the level of PDF1.2 mRNA in pad4 plants was much higher than it was in wild-type plants (Fig. 7). In eds4 plants treated with either rose bengal or MeJA, PDF1.2 mRNA levels were higher than they were in similarly treated wild-type plants, although these differences were not as large as the difference between pad4 plants and wild-type plants (Fig. 7). These observations confirm and extend the correlation between reduced strength of SA signaling and increased strength of JA signaling. This correlation appears to be quantitative, since the defect in SA signaling in pad4 plants is more severe
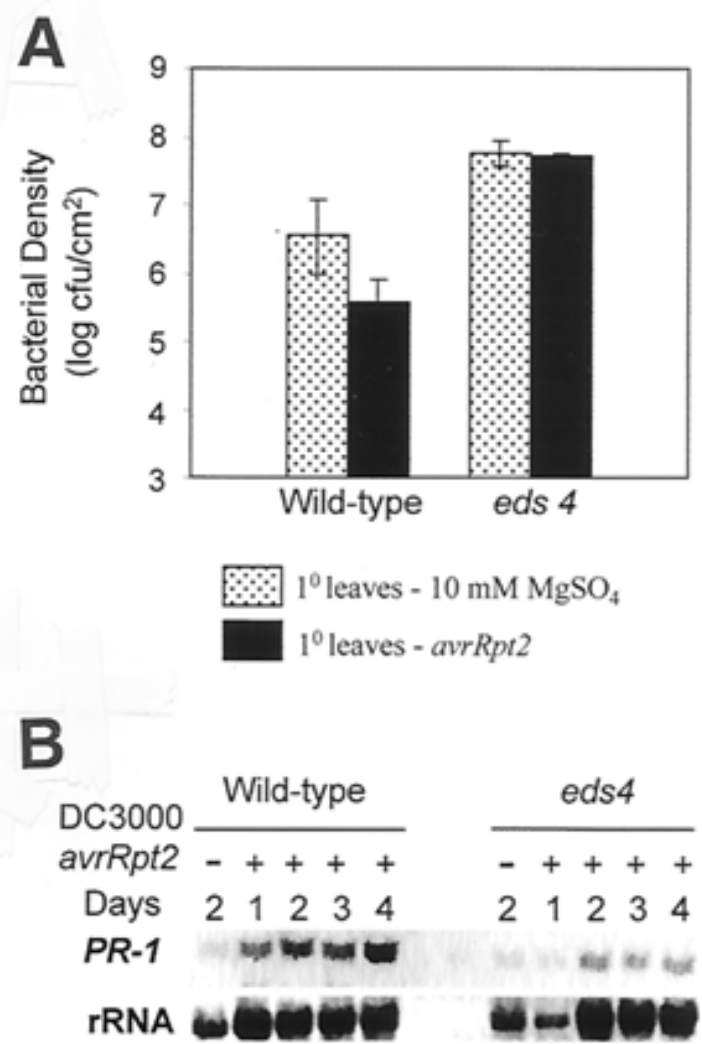

Fig. 5. A, Effect of systemic acquired resistance (SAR) induced by an avirulent pathogen on the growth of Pseudomonas syringae pv. maculicola $(P s m)$ ES4326. Four to five half-leaves of each plant were infected with $P$. syringae pv. tomato (Pst) DC3000 carrying avrRpt2 at a dose of $10^{4} \mathrm{CFU} / \mathrm{cm}^{2}$ leaf area or with $10 \mathrm{mM} \mathrm{MgSO}$. Four days after infection, two secondary leaves of each plant were infected with Psm ES4326. Bacterial titer was measured 3 days after infection. Each bar represents the mean and standard deviation of six replicates. B, Systemic expression of $P R-1$ in wild-type and eds 4 plants. One half of each of three leaves per plant was infected with Pst DC3000 carrying avrRpt2 at a dose of $10^{4} \mathrm{CFU} / \mathrm{cm}^{2}$. Control plants were mock-infected with $10 \mathrm{mM}$ $\mathrm{MgSO}_{4}$. Uninfected leaves were excised at $1,2,3$, and 4 days after infection with the bacteria. Uninfected leaves from mock-infected samples were excised at 2 days after infection. 18S rRNA was used as the loading control. Similar results were obtained in replicate experiments. 
than the defect in eds 4 plants (judged by $P R-1$ expression in response to Psm ES4326 infection) and the enhanced expression of PDF1.2 is also greater in pad4 plants than it is in eds 4 plants.

\section{Mapping and complementation of eds4.}

The eds4-1 mutation was previously shown to segregate as a single recessive mutation (Glazebrook et al. 1996). This observation was confirmed in the second and third backcrosses of $e d s 4-1$ plants to wild type. Among the $\mathrm{F}_{2}$ progeny of these crosses, 11 plants were scored as eds and 35 were scored as wild type, based on the extent of bacterial growth 3 days after
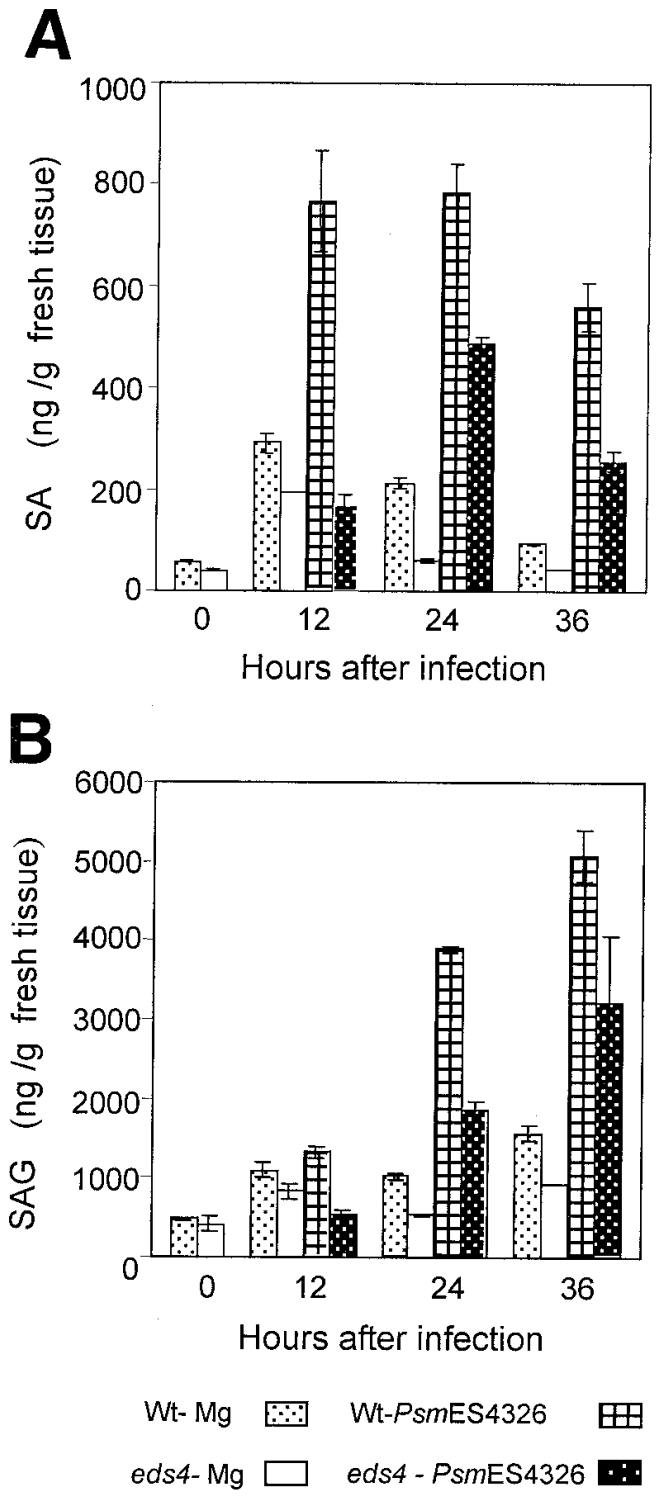

Fig. 6. Salicylic acid (SA) and SA glucoside (SAG) levels in infected wild-type and $e d s 4$ plants. Wild-type and $e d s 4$ plants were infected with Pseudomonas syringae pv. maculicola (Psm) ES4326 or mock-infected with $10 \mathrm{mM} \mathrm{MgSO}$. Leaves were collected at 12,24 , and $36 \mathrm{~h}$ after infection. Each column represents the mean of three replicate samples. Error bars representing the standard deviations are shown where they are large enough to be visible. Free SA and total SA (SA + SAG) were assayed on the same samples. SAG values were obtained by subtracting free SA from total SA in each sample. A, Free SA. B, SAG. infection. These data are consistent with a 1:3 ratio $\left(\chi^{2}=0.03\right.$, $P>0.8$ ), indicating that $e d s 4-1$ is a single recessive mutation.

In an effort to place EDS4 on the genetic map, eds 4 plants (Columbia ecotype) were crossed to wild-type Landsberg plants. One hundred and forty $\mathrm{F}_{2}$ plants from this cross were scored for the eds phenotype. Unlike the case of backcrosses to Columbia, no clear segregation was observed. Rather, bacterial titers varied over a continuous range, indicating that genes other than eds 4 that are segregating in the Columbia $\times$ Landsberg cross affect the bacterial growth phenotype. The camalexin-deficient phenotype conferred by pad4 also shows aberrant segregation in a Columbia $\times$ Landsberg cross, but it segregates $1: 3$ in a Columbia $\times$ Keswick cross (Zhou et al. 1998). Consequently, eds 4 was crossed to wild-type Keswick plants. Like $\mathrm{F}_{2}$ plants from the Landsberg cross, $99 \mathrm{~F}_{2}$ plants from this cross also displayed a continuous range of bacterial titers, indicating that there are genes other than eds 4 that affect bacterial growth segregating in this cross also. Not surprisingly, efforts to determine a map position for eds4, assuming that one-fourth of the $F_{2}$ plants with the highest bacterial titers were $e d s 4$ homozygotes, were unsuccessful.

There are three other Arabidopsis mutants that accumulate low levels of SA in response to $P$. syringae infection: pad4, eds5/sid1, and sid2 (Nawrath and Metraux 1999; Rogers and Ausubel 1997; Zhou et al. 1998). All four pad4 mutations cause a reduction in camalexin synthesis, while camalexin synthesis in $e d s 4$ plants is indistinguishable from that in wildtype plants, so it is extremely unlikely that eds 4 is an allele of pad4. Complementation testing of eds5 and eds4 (Glazebrook et al. 1996) and sid2 and eds4 (data not shown) for the Psm ES4326 growth phenotype demonstrated that eds4 is not allelic to eds 5 or sid2. Like the eds 4 mutation, nprl mutations block activation of $P R-1$ expression in response to SA. However, $n p r l$ plants accumulate even more $\mathrm{SA}$ in response to $P$. syringae infection than wild-type plants do, in contrast to the reduced SA levels in $e d s 4$ plants. Complementation testing of eds4 and nprl-1 for the Psm ES4326 growth phenotype demonstrated that eds 4 is not an $n p r l$ allele (data not shown).

\section{DISCUSSION}

The phenotypes of eds 4 plants demonstrate that EDS4 functions in SA-dependent control of defense gene expression. After infection with Psm ES4326, SA and SAG levels in eds4 plants are much lower than in similarly treated wild-type plants. Presumably, this reduction in SA levels is the cause of

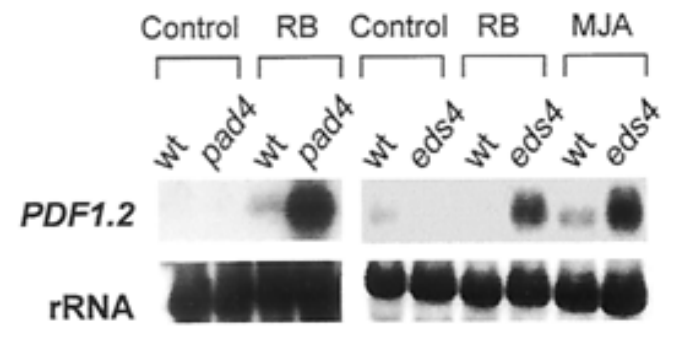

Fig. 7. PDF1.2 expression in wild-type, pad4, and eds 4 plants. Expression of PDF1.2 (defensin) gene in the leaves of wild-type, pad4, and $e d s 4$ plants treated with methyl jasmonate (MJA) or rose bengal (RB) or untreated (Control). The tissues were excised at 2 days after treatment. $18 \mathrm{~S}$ rRNA was used as a control for equal loading. 
the reduced $P R-1$ transcript levels and increased bacterial growth in infected $e d s 4$ plants. The $e d s 4$ mutation also causes reduced sensitivity to $\mathrm{SA}$. In $e d s 4$ seedlings, the concentration of exogenous SA required to trigger $P R-1$ expression is higher than the concentration required by wild-type seedlings. There are at least two possible explanations for these results, as shown in Figure 8. One possibility is that EDS4 encodes a negative regulator of SA turnover (Fig. 8A). In this model, eds 4 mutations would cause reduced accumulation of SA in infected leaves and reduced responsiveness to SA by reducing the intracellular concentration of SA. Another possibility is that EDS4 acts downstream from SA, explaining the observation that $e d s 4$ plants respond weakly to SA (Fig. $8 \mathrm{~B}$ ). In this model, EDS4 also participates in an SA amplification loop,

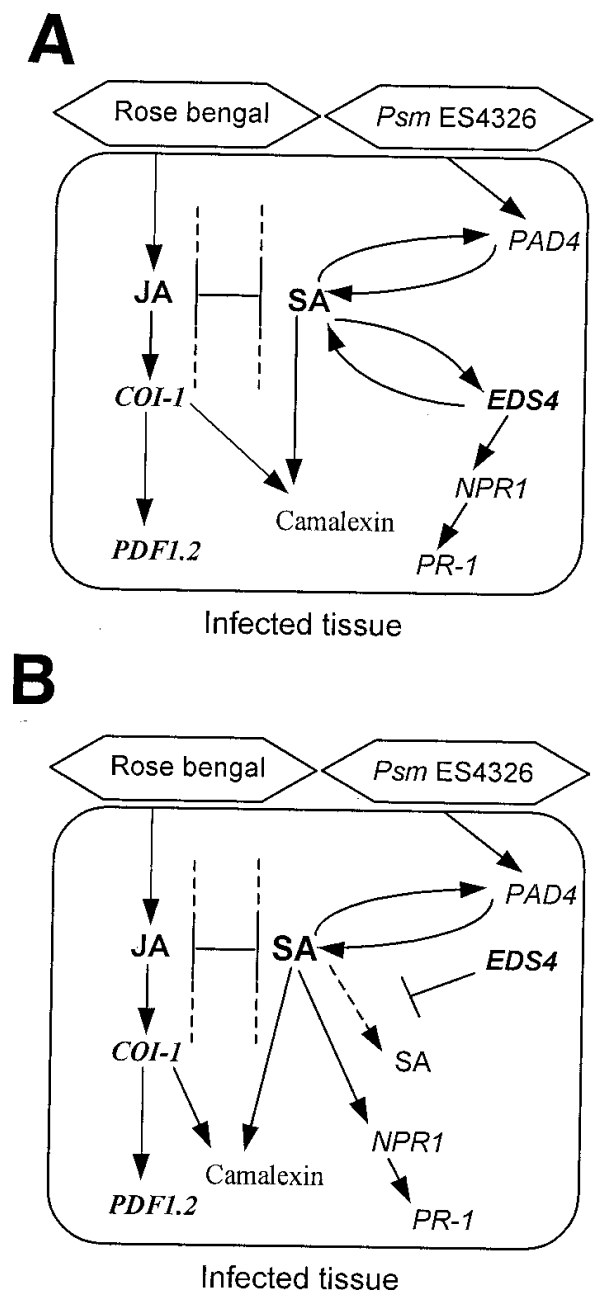

Fig. 8. Models of the role of EDS4 in signal transduction. In response to infection by Pseudomonas syringae pv. maculicola (Psm) ES4326, PAD4 acts in a positive autoregulatory loop to increase salicylic acid (SA) concentrations. This increase is required for camalexin synthesis and $P R-1$ expression. A, EDS4 acts in elevating SA levels by either coding for a negative regulator of SA turnover, or $\mathbf{B}$, by participating in an SA amplification loop and in responding to SA, in a manner that contributes to activation of $P R-1$ expression but does not affect camalexin synthesis. NPR1 is required for activation of $P R-1$ expression but not for elevation of SA levels. SA signaling and JA signaling are mutually inhibitory, yet both signals are required for camalexin production. The rationale for these models and alternative explanations for the phenotypes of $e d s 4$ plants are presented in the Discussion. explaining the observation that SA levels are low in infected eds 4 plants. The eds 4 mutation does not completely block accumulation of SA or responses to SA. In either model, these effects could be due to residual function of eds4, or due to EDS4-independent SA signaling. Other genes are known to be required for accumulation of SA after Psm ES4326 infection, including PAD4 and EDS5/SID1 (Zhou et al. 1998; Nawrath and Metraux 1999).

NPR1 is required for activation of $P R-1$ expression in response to SA. When nprl plants are infected with Psm ES4326, SA levels are higher than they are in infected wildtype plants (Cao et al. 1994). This suggests that NPR1 is required only for responses to SA, and not for production of SA. Consequently, EDS4 is placed upstream from NPR1 in the signaling pathway. There is a formal possibility that EDS4 and NPR1 act in parallel pathways, rather than EDS4 acting through NPR1 (Fig. 8B). This seems unlikely, since nprl mutations block SA-induced $P R-1$ expression completely.

PAD4 is required for activation of SA signaling in response to Psm ES4326 infection. SA levels in infected pad4 plants are lower than in infected wild-type plants, but pad4 mutants do not show a defect in response to SA (Zhou et al. 1998). PAD4 also seems to be involved in SA signal amplification, since $\mathrm{SA}$ is required for pathogen-induced $P A D 4$ expression, and PAD4 is required for SA accumulation (Jirage et al. 1999). Consequently, we have placed PAD4 upstream from $\mathrm{SA}$, and postulated that it participates in amplification of SA levels in infected tissue.

The eds 4 and pad4 mutations both cause enhanced expression of the defensin gene $P D F 1.2$ in response to treatment with rose bengal. Expression of PDF1.2 is a JA- and ethylenedependent process that does not require SA (Penninckx et al. 1996, 1998). As described above, it is known that SAdependent signaling and JA-dependent signaling can be mutually inhibitory. Both eds 4 and pad4 mutations interfere with SA-dependent signaling. Presumably, the reduction in SAdependent signaling in eds 4 and pad4 plants relieves inhibition of JA-dependent signaling, leading to increased PDF1.2 expression in response to rose bengal treatment. This effect appears to be quantitative, since $e d s 4$ has a weaker effect on SA signaling than pad4 (judged by $P R-1$ RNA levels after Psm ES4326 infection), and it has a correspondingly weaker effect on PDF1.2 RNA levels after rose bengal treatment.

Unlike eds 4 plants, pad4 plants have a defect in camalexin synthesis after Psm ES4326 infection. The camalexin defect seems to be due to the reduced SA level in infected pad4 plants, since treatment with exogenous SA effectively restores camalexin synthesis. SA is necessary for camalexin synthesis, since $n a h G$ plants are severely compromised for camalexin synthesis after infection by Psm ES4326 or Psm ES4326 carrying avrRpt2. SA is not sufficient to induce camalexin synthesis, since plants treated with SA do not produce camalexin. The levels of free SA in Psm ES4326-infected eds4 plants (25, 60 , and $50 \%$ of wild type at 12,24 , and $36 \mathrm{~h}$, respectively) are comparable to those in infected pad4 plants $(25,66$, and $55 \%$ of wild type at 12,24 , and $36 \mathrm{~h}$, respectively), yet eds 4 plants do not have a camalexin defect. There are several possible explanations for this observation.

The first explanation is based on the observation that despite the similar free SA levels in eds 4 and pad4 plants, the SA-signaling defect caused by pad4 seems to be more severe. 
The $P R-1$ mRNA level in infected pad4 plants is lower than in infected eds 4 plants, and the total SA level in infected pad4 plants (30\% of wild type) is lower than in infected eds 4 plants (60\% of wild type). It is possible that the SA defect in eds 4 plants is not severe enough to cause a camalexin defect. The severity of the pad4 mutation could be exacerbated by its effect on JA signaling. Camalexin synthesis after Psm ES4326 infection may require JA signaling as well as SA signaling, since JA-insensitive coil plants synthesize very little camalexin after Psm ES4326 infection (Zhou et al. 1999). Since SA and JA signaling are mutually inhibitory, a process that requires both SA and JA signaling would probably require a fine balance of both signals. In pad4 plants, JA signaling seems strongly enhanced, while SA signaling is greatly weakened. Both effects are less severe in $e d s 4$ plants. Perhaps the skewed ratio of SA and JA signal strength interferes with activation of camalexin synthesis in pad4 plants.

The eds5/sid1 and sid 2 mutants have very low levels of SA, very low $P R-1$ expression, and normal camalexin levels in leaves infected with $P$. syringae. Since the severity of the $e d s 5 /$ sid 1 and sid 2 effects on SA and $P R-1$ expression is comparable to that of the $n a h G$ transgene, it is difficult to argue that the reason that these mutations do not affect camalexin accumulation is that they are insufficiently severe. The eds5/sid1 and sid2 mutations did not cause hypersensitivity to activation of PDF1.2 expression by Alternaria brassicicola infection, but it remains possible that such an effect would be observed if the inducer was rose bengal or MeJA. Nawrath and Metraux (1999) have proposed that eds5/sidl and sid2 interfere with an SA-independent negative regulation of camalexin, presumably compensating for their negative effect on SA-dependent activation of SA biosynthesis. If this model is correct, $e d s 4$ phenotypes could be explained similarly, or by using the reduced-severity explanation we propose above.

A second possible explanation is that pad4 and the nahG transgene affect an as yet undiscovered signaling pathway that is required for activation of camalexin synthesis and is not affected by eds 4 , eds $5 /$ sidl, or sid2. If this is true, then it must be possible to overcome the requirement for the unknown signal by supplying large amounts of exogenous SA, since SA treatment restores camalexin synthesis in pad4 plants. The phenotype of $n a h G$ plants is widely assumed to reflect the loss of SA, but of course it is not possible to exclude the possibility that it has additional effects. A mutation that blocked the SA biosynthetic pathway would be very useful for resolving these issues.

EDS4 is required for biologically induced SAR. Experiments with $n a h G$ plants demonstrated that SA is required in systemic tissue for SAR (Vernooij et al. 1994). The SAR defect in eds 4 plants could be due to reduced responsiveness to $\mathrm{SA}$, inadequate SA concentration in the systemic tissue, or both. Mutations in NPRl, which block SA-induced gene expression, also abolish SAR (Cao et al. 1994), as do mutations in eds5/sid1 and sid2, which block SA production (Nawrath and Metraux 1999).

Future work will be directed toward isolating EDS4 and characterizing double mutants homozygous for both eds 4 and mutations that cause constitutive defense gene expression. These experiments should help to elucidate the mechanism of EDS4 action, and to further define its position in the signal transduction network controlling activation of defense responses.

\section{MATERIALS AND METHODS}

\section{Plants and growth conditions.}

Wild-type plants were Arabidopsis thaliana accession Columbia (Col), eds 4 plants were eds4-1 homozygotes that had been backcrossed to the wild-type parent $(\mathrm{Col})$ at least twice, and pad4 plants were pad4-1 homozygotes that had been backcrossed to the wild-type parent (Col) four times (Glazebrook et al. 1996). Generally, plants were grown in pots in Metro-Mix 200 soil (Scotts-Sierra Horticultural Products, Marysville, $\mathrm{OH}$ ) in a Conviron (Pembina, ND) growth chamber at $22 \pm 2^{\circ} \mathrm{C}, \quad 85 \%$ relative humidity, $100 \mu \mathrm{E}$ $\mathrm{s}^{-1} \mathrm{~m}^{-2}$ fluorescent illumination on a 12-h light/dark cycle. Fully expanded leaves of 4-week-old plants were used for the experiments. For measurement of the bacterial titer in response to SA, some plants were grown in a constant temperature room at $23^{\circ} \mathrm{C}$ and $50 \%$ relative humidity. For measurement of SA levels, plants were grown in a Conviron chamber as described above, except that an 8-h light, 16-h dark cycle was used to obtain more leaves per plant and fully expanded leaves from 8-week-old plants were used. Seedlings were grown on plates containing Murashige-Skoog (MS) medium (Life Technologies, Rockville, MD) and various concentrations of sodium salicylate. Seeds were vernalized at $4^{\circ} \mathrm{C}$ for 2 days before placement in a growth environment. The plates were incubated under fluorescent lamps $\left(100 \mu \mathrm{E} \mathrm{s}^{-1} \mathrm{~m}^{-2}\right)$ on a 24-h photo-period and $23^{\circ} \mathrm{C}$ (room temperature).

\section{Inoculations with bacteria and treatment with chemicals.}

Strains Psm ES4326 (Dong et al. 1991) and Pst DC3000 (Cuppels 1986) have been described. The avirulence gene avrRpt 2 was carried on plasmid pLH12 as described (Dong et al. 1991). P. syringae strains were grown in King's B medium supplemented with appropriate antibiotics (Glazebrook and Ausubel 1994). Bacterial suspensions were infiltrated into Arabidopsis plants as described previously (Glazebrook and Ausubel 1994). For experiments involving extraction of total RNA from infected leaves, Psm ES4326 or Psm ES4326 carrying avrRpt2 was introduced at a dose of $10^{4} \mathrm{CFU} / \mathrm{cm}^{2}$ leaf area (equivalent to $\mathrm{OD}_{600}=0.002$ ). For determination of bacterial growth, plants were infected with Psm ES4326 and Psm ES4326 carrying avrRpt2 at a dose of $10^{3} \mathrm{CFU} / \mathrm{cm}^{2}$ leaf area (equivalent to $\mathrm{OD}_{600}$ $=0.0002$ ). Leaves were excised and bacterial growth was assayed as described (Glazebrook et al. 1996). Data are reported as means and standard deviations of the $\log \left(\mathrm{CFU} / \mathrm{cm}^{2}\right)$ of at least six replicates. For determination of bacterial growth during SAR, four to five half-leaves of each plant were infected with Pst DC3000 carrying avrRpt2 at a dose of $10^{4} \mathrm{CFU} / \mathrm{cm}^{2}$ leaf area (equivalent to $\mathrm{OD}_{600}=0.002$ ). Four days after infection, bacterial growth was measured in the systemic leaves by infecting two leaves of each plant with Psm ES4326, as described above. For treatment with SA, plants were sprayed with $5 \mathrm{mM}$ sodium salicylate with $0.02 \%$ Silwet L-77 to reduce surface tension. Control plants were sprayed with water containing $0.02 \%$ Silwet L-77. Rose bengal $(20 \mathrm{mM})$ and MeJA $(45 \mu \mathrm{M}$ in $0.1 \%$ [vol/vol] ethanol) were applied as 5- $\mu$ l droplets on leaves (five drops per leaf) (Penninckx et al. 1996).

\section{RNA blot analysis.}

Tissue samples consisting of five to six leaves were collected and frozen in liquid nitrogen and stored at $-80^{\circ} \mathrm{C}$. Total 
RNA was extracted and $5 \mu \mathrm{g}$ of RNA per sample was separated on formaldehyde-agarose gels (Reuber and Ausubel 1996). After the samples were blotted onto Hybond- $\mathrm{N}^{+}$membrane (Amersham, Arlington Heights, IL), hybridizations were performed with various digoxigenin-labeled probes described below, followed by washes in $0.5 \times$ SSC $(1 \times$ SSC is $0.15 \mathrm{M} \mathrm{NaCl}$ plus $0.015 \mathrm{M}$ sodium citrate) at $65^{\circ} \mathrm{C}$ and chemiluminescent detection with CSPD or CDP star according to instructions provided by the supplier (Boehringer Mannheim, Indianapolis, IN). For hybridization with more than one probe, blots were stripped and re-probed. Singlestranded DNA probes for $P R-1, P R-5$ (Uknes et al. 1992), and $B G L-2$ (Dong et al. 1991) were prepared as described (Zhou et al. 1998). The single-stranded $P D F 1.2$ probe was made with SP6 primer (5'-CTATAGTGTCACCTAAAT-3') and EcoRIlinearized plasmid pZL1 (Life Technologies, Rockville, MD) containing the expressed sequence tag (EST) with GenBank accession number T04323 (obtained from the Arabidopsis Biological Resource Center). For ASA1 (Niyogi and Fink 1992) and 18S rRNA, single-stranded probes were made as described (Zhou et al. 1998). The $18 \mathrm{~S}$ rRNA probe was used to assess equal loading of RNA samples.

For quantitation of hybridization signals, the alkaline phosphatase substrate Attophos (Amersham, Piscataway, NJ) was applied to the blots according to the instructions of the supplier. The fluorescent product was quantitated with a Storm Phosphorimager (Molecular Dynamics, Sunnyvale, CA).

\section{Determination of endogenous levels of SA.}

Mature leaves of 7-week-old wild-type and pad4 plants were infected with Psm ES4326 at a dose of $10^{4} \mathrm{CFU} / \mathrm{cm}^{2}$ (equivalent to $\mathrm{OD}_{600}=0.002$ ) or mock-infected with $10 \mathrm{mM}$ $\mathrm{MgSO}_{4}$. At intervals after infection, leaves were collected $(1 \mathrm{~g}$ of tissue per sample, approximately seven plants) and frozen in liquid nitrogen. Free SA and total SA were determined as described previously (Bowling et al. 1994). SAG was determined by subtracting the free SA value from the total SA value.

\section{ACKNOWLEDGMENTS}

Much of this work was carried out in the Center for Agricultural Biology of the University of Maryland Biotechnology Institute, and supported by NSF grant MCB 9723493 to J. G. We are grateful to Fumiaki Katagiri for critical reading of the manuscript and Christiana Nawrath for the gift of sid2 seed.

\section{LITERATURE CITED}

Baker, B., Zambryski, P., Staskawicz, B., and Dinesh-Kumar, S. P. 1997. Signaling in plant microbe interactions. Science 276:726-733.

Bowling, S. A., Guo, A., Cao, H., Gordon, A. S., Klessig, D. F., and Dong, X. 1994. A mutation in Arabidopsis that leads to constitutive expression of systemic acquired resistance. Plant Cell 6:1845-1857.

Cao, H., Bowling, S. A., Gordon, S., and Dong, X. 1994. Characterization of an Arabidopsis mutant that is nonresponsive to inducers of systemic acquired resistance. Plant Cell 6:1583-1592.

Clarke, J. D., Liu, Y., Klessig, D. F., and Dong, X. 1998. Uncoupling PR gene expression from NPRI and bacterial resistance: Characterization of the dominant Arabidopsis cpr6-1 mutant. Plant Cell 10:557-569.

Cuppels, D. A. 1986. Generation and characterization of Tn5 insertion mutations in Pseudomonas syringae pv. tomato. Appl. Environ. Microbiol. 52:323-327.

Delaney, T., Uknes, S., Vernooij, B., Friedrich, L., Weymann, K., Negrotto, D., Gaffney, T., Gut-Rella, M., Kessmann, H., Ward, E., and
Ryals, J. 1994. A central role of salicylic acid in plant disease resistance. Science 266:1247-1250.

Delaney, T. P., Friedrich, L., and Ryals, J. A. 1995. Arabidopsis signal transduction mutant defective in chemically and biologically induced disease resistance. Proc. Natl. Acad. Sci. USA 92:6602-6606.

Dong, X., Mindrinos, M., Davis, K. R., and Ausubel, F. M. 1991. Induction of Arabidopsis defense genes by virulent and avirulent Pseudomonas syringae strains and by a cloned avirulence gene. Plant Cell 3: 61-72.

Durner, J., Wendehenne, D., and Klessig, D. F. 1998. Defense gene induction in tobacco by nitric oxide, cyclic GMP, and cyclic ADPribose. Proc. Natl. Acad. Sci. USA 95:10328-10333.

Epple, P., Apel, K., and Bohlmann, H. 1995. An Arabidopsis thaliana thionin gene is inducible via a signal transduction pathway different from that for pathogenesis-related proteins. Plant Physiol. 109:813820 .

Feys, B. J. F., Benedetti, C. E., Penfold, C. N., and Turner, J. G. 1994. Arabidopsis mutants selected for resistance to the phytotoxin coronatine are male sterile, insensitive to methyl jasmonate, and resistant to a bacterial pathogen. Plant Cell 6:751-759.

Gaffney, T., Friedrich, L., Vernooij, B., Negrotto, D., and Nye, G. 1993. Requirement of salicylic acid for the induction of systemic acquired resistance. Science 261:754-756.

Glazebrook, J., and Ausubel, F. M. 1994. Isolation of phytoalexindeficient mutants of Arabidopsis thaliana and characterization of their interactions with bacterial pathogens. Proc. Natl. Acad. Sci. USA 91: 8955-8959.

Glazebrook, J., Rogers, E. E., and Ausubel, F. M. 1996. Isolation of Arabidopsis mutants with enhanced disease susceptibility by direct screening. Genetics 143:973-982.

Hammond-Kosack, K. E., and Jones, J. D. G. 1996. Resistance genedependent plant defense responses. Plant Cell 8:1773-1791.

Harms, K., Ramirez, I., and Pena-Cortes, H. 1998. Inhibition of wound induced accumulation of allene oxide synthase transcripts in flax leaves by aspirin and salicylic acid. Plant Physiol. 118:1057-1065.

Jirage, D., Tootle, T. T., Reuber, T. L., Frost, L. N., Feys, B. J., Parker, J. E., Ausubel, F. M., and Glazebrook, J. 1999. Arabidopsis thaliana $P A D 4$ encodes a lipase-like gene that is important for salicylic acid signaling. Proc. Natl. Acad. Sci. USA 96:13583-13588.

Lawton, K., Weymann, K., Friedrich, L., Vernooij, B., Uknes, S., and Ryals, J. 1995. Systemic acquired resistance in Arabidopsis requires salicylic acid but not ethylene. Mol. Plant-Microbe Interact. 8:863870 .

Mindrinos, M., Katagiri, F., Yu, G.-L., and Ausubel, F. M. 1994. The Arabidopsis thaliana disease resistance gene RPS2 encodes a protein containing a nucleotide-binding site and leucine-rich repeats. Cell 78: 1856-1860.

Nawrath, C., and Metraux, J.-P. 1999. Salicylic acid induction-deficient mutants of Arabidopsis express $P R-2$ and $P R-5$ and accumulate high levels of camalexin after pathogen inoculation. Plant Cell 11:13931404.

Niki, T., Mitsuhara , I., Seo, S., Ohtsubo, N., and Ohashi, Y. 1998. Antagonistic effect of salicylic acid and jasmonic acid on the expression of pathogenesis related (PR) protein genes in wounded mature tobacco leaves. Plant Cell Physiol. 39:500-507.

Nishiuchi, T., Hamada, T., Kodama, H., and Iba, K. 1997. Wounding changes the spatial expression pattern of the Arabidopsis plastid $\omega-3$ fatty acid desaturase gene (FAD7) through different signal transduction pathways. Plant Cell 9:1701-1712.

Niyogi, K. K., and Fink, G. R. 1992. Two anthranilate synthase genes in Arabidopsis: Defense-related regulation of the tryptophan pathway. Plant Cell 4:721-723.

Penninckx, I., Eggermont, K., Terras, F., Thomma, B., Samblanx, G., Buchala, A., Metraux, J.-P., Manners, J., and Broekaert, W. 1996. Pathogen-induced systemic activation of a plant defensin gene in Arabidopsis follows a salicylic acid-independent pathway. Plant Cell 8:2309-2323.

Penninckx, I. A. M. A., Thomma, B. P. H. J., Buchala, A., Metraux, J., and Broekaert, W. F. 1998. Concomitant activation of jasmonate and ethylene response pathways is required for induction of a plant defensin gene in Arabidopsis. Plant Cell 10:2103-2113.

Reuber, T. L., and Ausubel, F. 1996. Isolation of Arabidopsis genes that differentiate between resistance responses mediated by the RPS 2 and RPM1 disease resistance genes. Plant Cell 8:241-249. 
Reuber, T. L., Plotnikova, J. M., Dewdney, J., Rogers, E. E., Wood, W., and Ausubel, F. M. 1998. Correlation of defense gene induction defects with powdery mildew susceptibility in Arabidopsis enhanced disease susceptibility mutants. Plant J. 16:473-485.

Rogers, E. E., and Ausubel, F. M. 1997. Arabidopsis enhanced disease susceptibility mutants exhibit enhanced susceptibility to several bacterial pathogens and alterations in $P R-1$ gene expression. Plant Cell 9:305-316

Ryals, J. A., Neuenschwander, U. H., Willits, M. G., Molina, A., Steiner, H.-Y., and Hunt, M. D. 1996. Systemic acquired resistance. Plant Cell 8:1809-1819.

Shah, J., Tsui, F., and Klessig, D. F. 1997. Characterization of a salicylic acid-insensitive mutant (sail) of Arabidopsis thaliana, identified in a selective screen utilizing the SA-inducible expression of the tms 2 gene. Mol. Plant-Microbe Interact. 10:69-78.

Uknes, S., Mauch-Mani, B., Moyer, M., Potter, S., Williams, S., Dincher, S., Chandler, D., Slusarenko, A., Ward, E., and Ryals, J. 1992. Acquired resistance in Arabidopsis. Plant Cell 4:645-656.
Vernooij, B., Friedrich, L., Morse, A., Reist, R., Kolditz-Jawhar, R., Ward, E., Uknes, S., Kessmann, H., and Ryals, J. 1994. Salicylic acid is not the translocated signal responsible for inducing systemic acquired resistance but is required in signal transduction. Plant Cell 6:959-965.

Willits, M. G., and Ryals, J. A. 1998. Determining the relationship between salicylic acid levels and systemic acquired resistance induction in tobacco. Mol. Plant-Microbe Interact. 11:795-800.

Zhang, Y., Fan, W., Kinkema, M., Li, X., and Dong, X. 1999. Interaction of NPR1 with basic leucine zipper protein transcription factors that bind sequences required for salicylic acid induction of the $P R-1$ gene. Proc. Natl. Acad. Sci. USA 96:6523-6528.

Zhou, N., Tootle, T. L., and Glazebrook, J. 1999. PAD3 Encodes an Arabidopsis cytochrome P450 monooxygenase required for camalexin synthesis. Plant Cell 11:2419-2428.

Zhou, N., Tootle, T. T., Tsui, F., Klessig D. F., and Glazebrook, J. 1998. PAD4 functions upstream from salicylic acid to control defense responses in Arabidopsis. Plant Cell 10:1021-1030. 